is possibly not quite so simple as it appears, and I certainly prefer as an alternative

$a \nabla_{8} / Q$

which can be rewritten

$V s / V$.

When this substitution is made, the two White equations become respectively

$$
V s / V=2 \cdot 40\left(V s / g^{2 / 5} Q^{1 / 5}\right)^{0 \cdot 78}
$$

and

$$
S=0.0120\left(V s / g^{2 / 5} Q^{1 / 5}\right)^{0 \cdot 90} .
$$

Now, if we demand of our equations that they possess a physical signiflcance, the conclusion is inescapable that, for a constant load $N$,

$$
V s / V \infty S \text {, }
$$

and

$$
V s \infty(V S) .
$$

I conclude that owing to the complex nature of Prof. White's dependent slope variable, and the relatively large errors of fleld measurement both in $S$ and $V 8$, he has inadvertently succeeded in deriving two different equations for the same concept, slope. His terminal velocity of the particle $V s$ plays the same part as the criterion I have adopted ( $V S)$, and I have no doubt that when he examines a more extended and reliable rollection of data he will succeed in reconciling his two powers of 0.78 and 0.90 respectively. The arithmetical mean of the two powers is 0.840 and differs very little from my power of 0.833 . I would be the last person in the world to suggest that "bed material is unimportant" : but it is indeed important to note that an equation of the engineer to the equation

$$
S=2^{1 / 6}(V S)^{5 / 6} /\left(g^{2} Q\right)^{1 / 6},
$$

in which $(V S)$ associates particle size with transported load, and is a convenient description of any alluvial channel. To the physicist, I recommend investigation of the new basic equation

$$
S=2 V^{5} / g^{2} Q
$$

An expression of this form may ultimately prove to be universal in its application.

$$
\begin{gathered}
\text { Thomason College, } \\
\text { Roorkee, } \\
\text { U.P., India. }
\end{gathered}
$$

Gerald Lacey

Sept. 6.

1 Nature, 158, 166 (1946).

Lindley, E. S., Proc. Punjab Eng. Congress, 7 (1919).

\section{Effect of Environment on the Reactivity of High Polymers}

DURING the polymerization of vinyl compounds, in the pure state and in solution, it is frequently observed that the reaction-rate curve is of the 'autocatalytic' type, the velocity increasing as the reaction proceeds. Hitherto this has been attributed to $(a)$ non-isothermal character of the reaction, $(b)$ to the fact that the catalyst, or its products of dissociation if present, does not immediately react with th monomer. In 1941 Schulz and Blaschke ${ }^{1}$ observed a slmilar increase in the velocity after about 20 per cent polymerization when neithe of the above explanations was valid. Similarly, Norrish and Smith found the same phenomenon in solution, the increase in velocity being the more marked the poorer the solvent for the polymer produced. Again, Trommsdorff ${ }^{3}$ found that if the viscosity of monomeric methyl methacrylute were increased by the addition of cellulose tripropionate, the velocity of polymerization and also the molecula weight of the polymethacrylate both increased.

The increase in rate might have been due $(a)$ to an increase in rate of initiation of polymer chains, $(b)$ an increase in the rate of propagation of growth, termination occurring by the mutual interaction of the ends of the active polymer. The effect could be produced either by an increase in viscosity of the solution or by precipitating the polymer out of solution, probably in the act of growing. An increase in $(a)$ is not compatible with the observed increase in molecular. weight, for normally an increase in $(a)$ would lead to a decrease in molecular to see how this rate could increase.

The most probable explanation appeared to be that the rate of termination was cut down. As the liquid beoame more viscous, the ends of the active polymer would find it more difficult to diffuse into each other's proximity and interact and so terminate growth. In the case of a bad solvent the active polymer would then be so coiled up case of a bad solvent the active polymer would then be so coiled up Thus in both cases the rate of polymerization would increase simply owing to a diminution of the speed of reaction responsible for cessation of growth.

Recently a method has been developed ${ }^{\star}$ for measuring the individua values of all the velocity coefficients in a polymerization reaction, and hence it appeared feasible to see whether in fact the ahove suggestion would account for the behaviour observed. Using the solvent techniqu with vinyl acetate and photochemical initiation of the reaction, pre-
cisely similar phenomena have been observed. In a good solvent such cisely similar phenomena have been observed. In a good solvent such as ethyl acetate, the reaction is normal and exactly similar to that in catalytic character of the reaction is clearly marked. The accompanying table shows the results obtained in the normal phase of the reaction and after acceleration had set in.
Rate of initiation of chains $=6.0 \times 10^{-8}$ mol. lit..$^{-1} \mathrm{sec}^{-1}$. Temp. $25^{\circ} \mathrm{C}$.

Overall rate (mol. lit. ${ }^{-1}$ sec. ${ }^{-1}$ )

Life-time of active polymer (sec.)

Termination coefficient,

(mol.-1 lit. sec.-1)

$$
\text { * After } 5 \text { per cent of polymer has been formed. }
$$

Abnormal

$17.0 \times 10^{-2}$
$6.8 \times 10^{2}$

Aer cent of polymer has been formed.

It is of importance to note that the values of $k p$ and $k t$ for the pure monomer, namely, $6 \cdot 7 \times 10^{2}$ and $2.5 \times 10^{\circ}$, are in excellent agreement with those for the normal phase of the reaction. In the abnorma phase of the reaction, however, only the termination coefficient is affected, thus vindicating the suggestions made previously. The agreement is quantitatively satisfactory, for a two-fold increase in rate would correspond to a four-fold reduction in the termination coefficient, as is approximately observed. Thus the reactivity of growing polymer molecule is affected by the environment in which it i placed, provided that it interacts with another of its kind. Immobility or coiling up as in a bad solvent or in the gas phase cuts down reactivity On the other hand, when a monomer interacts with the polymer, it high mobility permits it to penetrate to the active spot under all conditions, and environment has no effect. A great many paralle observations on reaction of this kind all fall into quantitative agree ment when this new kind of effect is taken into account.

Chemistry Department,
University of Aberdeen.

G. M. BURNETT Sept. 4.

${ }^{1}$ Schulz and Blaschke, Z. physik. Chem., 50, 305 (1941).

Norrish and Smith, Nature, 150, 336 (1942).

Trommsdorff, Collonuium on High Polymers, Freiburg, 1944. See

B.I.O.S. Report No. 363, Item No. 22

4 Burnett and Melville, Nature, 156, 661 (1945).

\section{Alginic Acid Diacetate}

BaLIEviNg that the usual methods of acetylation give degraded products, Wassermann ${ }^{1}$ has attempted to acetylate alginic acid with ketene. By this means he succeeded in introducing approximately one acetyl group into each repeating unit of the polymer. Some years ago we studied the action of ketene on alginic acid under various conditions, and although products with a higher acetyl content $(20.9$ in favour of a simpler and more effective procedure ${ }^{2}$.

When alginic acid is dried, hydrogen bonding between neighbouring molecules is so severe, and the structure is so compact, that reaction with acetic anhydride is impossible. If, however, the alginic acid i first swollen in water, the hydroxyl groups become available for acetylation and remain available when the water is displaced with glacia acetic acid. Making use of this principle, alginic acid yarn ${ }^{8}$ can be acetylated without loss of flbre-form in the following way : the yarn $(1.0 \mathrm{gm}$.) is swollen in water, centrifuged and then immersed in several changes of glacial acetic acid until the residual water is less, preferably very much less, than 30 per cent of the original weight of the yarn. The latter is then transferred to $30-40$ c.c. of a mixture having the following composition: benzene $180 \mathrm{gm}$., acetic anhydride $60 \mathrm{gm}$. and sulphuric acid (conc.) $1 \cdot 2-1.5 \mathrm{gm}$. The reaction is allowed to proceed for 24 hours at $25^{\circ} \mathrm{C}$., or for 1 hour at $25^{\circ} \mathrm{C}$., followed by 15 minites at $50^{\circ}-60^{\circ} \mathrm{C}$. Perchloric acid can be used in place of sulphuric acid and either catalyst can be introduced by swelling the yarn with 1. $N$ solution of the acid instead of with water ; in this case, acetylation is carried out with a mixture of benzene and acetic anhydride.

Yarn acetylated for 17 hours at $25^{\circ} \mathrm{C}$. in the above manner gave
.

Yarn acetylated for 17 hours at $25^{\circ} \mathrm{C}$. in the above manner gave
a 97.3 ner cent yield of the di-acetate (acetyl : found, 33.0 per cent ; theory, 33.1 per cent). Determinations of the tenacity of the acetylated yarn, its solubility in water, and other properties showed that acetylayarn, its solubility in water, and other properties showed that acetylaAs would be expected, alginic acid di-acetate swells, but does not dissolve, in water, methanol, ethanol acetone, dioxan and glacial dissolve, in water, methanol, ethanol, acetone, dioxan and glacial acetone ( 80 per cent) and, surprisingly enough, in view of the insolubility aceton of calcium alginate, in 0.5 calcium acetate. Similarly, no precipitate could be obtained when solutions of calcium chloride, harium chloride, copper sulphate, lead acetate and ferric chloride

The di-acetate undergoes slow hydrolysis on exposure to air at 65 per cent relative humidity and $22 \cdot 2^{\circ} \mathrm{C}$., as is indicated by the following data for yarn acetylated in presence of sulphuric acid:

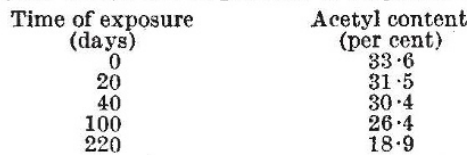

Similar results were obtained with yarn acetylated in presence of perchloric acid.

A full account of the preparation and properties of the di-acetate nd other esters of alginic acid will be published elsewhere. We are nd ebted to Alginate Industries, Ltd., and Coturtaulds, Ltd., for grants $\mathrm{n}$ aid of these investigations.

\section{N. H. Chambertuain}

J. B. SPEAKMAN

Textile Chemistry Laboratory,

University, Leeds.

Sept. 7.

1. Wassermann, Nature. 158, 271 (1946).

Cunningham, Chamberlu1n and Speakman, Brit. Pat. 573,591 (1945). - Speakman and Chamberlain J. Soc. Dyers ard Col., 60, 264 (1944). 